Article

\title{
Enhancing 2-Ketogluconate Production of Pseudomonas plecoglossicida JUIM01 by Maintaining the Carbon Catabolite Repression of 2-Ketogluconate Metabolism
}

\author{
Wenjing Sun ${ }^{1,2, *}$, Tjahjasari Alexander ${ }^{1}$, Zaiwei Man ${ }^{1, *}$, Fangfang Xiao ${ }^{1}$, Fengjie Cui ${ }^{1,2}$ and \\ Xianghui Qi ${ }^{1}$ \\ 1 School of Food and Biological Engineering, Jiangsu University, Zhenjiang 212013, China; \\ 1000003523@ujs.edu.cn (T.A.); $1000004769 @ u j s . e d u . c n$ (F.X.); 1000003286@ujs.edu.cn (F.C.); \\ 1000003420@ujs.edu.cn (X.Q.) \\ 2 Parchn Sodium Isovitamin C Co. Ltd., Dexing, 334221, China \\ * Correspondence: juswj@ujs.edu.cn (W.S.); qiangni.well@163.com (Z.M.)
}

Received: 19 September 2018; Accepted: 11 October 2018; Published: 13 October 2018

\begin{abstract}
Ketogluconate (2KGA) is an organic acid that is important for pharmaceutical, cosmetic, and environmental applications. Pseudomonas plecoglossicida JUIM01 strain is an important industrial 2KGA producer in China. In this paper, we found that P. plecoglossicida JUIM01 could convert glucose to 2KGA extracellularly, and the formed 2KGA was subsequently consumed after glucose was exhausted during the fermentation process. Experiments of glucose and 2KGA supplementation during fermentation process revealed that, only when glucose was exhausted, the strain started to consume the product 2KGA. Then, the mechanism of this phenomenon was investigated at transcription and protein levels, and the results indicated that P. plecoglossicida JUIM01 possesses carbon catabolite repression of 2KGA metabolism by glucose. Next, increasing the supply of glucose could attenuate 2KGA consumption and enhance the 2KGA yield from glucose. Finally, fed-batch fermentation of P. plecoglossicida JUIM01 resulted in $205.67 \mathrm{~g} / \mathrm{L}$ of $2 \mathrm{KGA}$ with a productivity of $6.86 \mathrm{~g} / \mathrm{L} / \mathrm{h}$ and yield of $0.953 \mathrm{~g} / \mathrm{g}$ glucose. These results can provide references for the industrial fermentation production of 2KGA and other fermentation products.
\end{abstract}

Keywords: Pseudomonas plecoglossicida; 2-ketogluconate consumption; transcription analysis; carbon catabolite repression; glucose supply

\section{Introduction}

2-Ketogluconate (2KGA) is an organic acid that is important for pharmaceutical, cosmetic, and environmental applications. It is a key intermediate in industrial manufacture of erythorbic acid (D-isoascorbic acid, a stereoisomer of ascorbic acid), an antioxidant widely used in food industry. Currently, microbial fermentation is the common method for 2KGA production. Microorganisms from genera Gluconobacter, Pseudogluconobacter, Pseudomonas, and Klebsiella have been used for 2KGA production. The strains Pseudomonas fluorescens AR4 and A46, and Pseudomonas plecoglossicida JUIM01, were screened by our group, and are used for industrial production of 2KGA in most Chinese erythorbic acid companies [1-7]. P. fluorescens AR4 strain could produce $135 \mathrm{~g} / \mathrm{L}$ of $2 \mathrm{KGA}$ under optimized conditions during batch fermentation, and this strain is suitable for the production of commercially acceptable levels of 2KGA in semi-continuous culture [3]. Metabolically engineered Gluconobacter suboxydans could produce $72.3 \mathrm{~g} / \mathrm{L}$ of $2 \mathrm{KGA}$ with a yield of $0.723 \mathrm{~g} / \mathrm{g}$ glucose [8]. Under optimum conditions, Klebsiella pneumoniae could produce $186 \mathrm{~g} / \mathrm{L}$ of $2 \mathrm{KGA}$ with a yield of $1.05 \mathrm{~g} / \mathrm{g}$ glucose [6]. 
Using biotransformation method, $60 \mathrm{~g} / \mathrm{L}$ resting cells (wet weight) of recombinant Gluconobacter oxydans strain could produce $321 \mathrm{~g} / \mathrm{L}$ of 2KGA from glucose [9].

The bacteria of genus Pseudomonas metabolize glucose almost exclusively by Entner-Doudoroff (ED) pathway (Figure 1) [10-12]. The extracellular glucose can be converted to gluconate and 2KGA by two consecutive periplasmic oxidation reactions catalyzed by glucose dehydrogenase and gluconate dehydrogenase. Meanwhile, the intracellular glucose, gluconate, and 2KGA are converted to 6-phosphogluconate, and further channeled into the ED pathway $[10,11,13,14]$. For P. putida KT2440 strain, more than $80 \%$ of the glucose influx is channeled through the periplasmic oxidation pathway via gluconate or 2KGA and only a minor fraction through glucose-6-phosphate, and this strain can also use gluconate or 2KGA as the sole carbon source [11]. P. fluorescens can convert most glucose to gluconate, and 2KGA, the formed gluconate, and 2KGA are subsequently assimilated by the strain after glucose depletion [13].

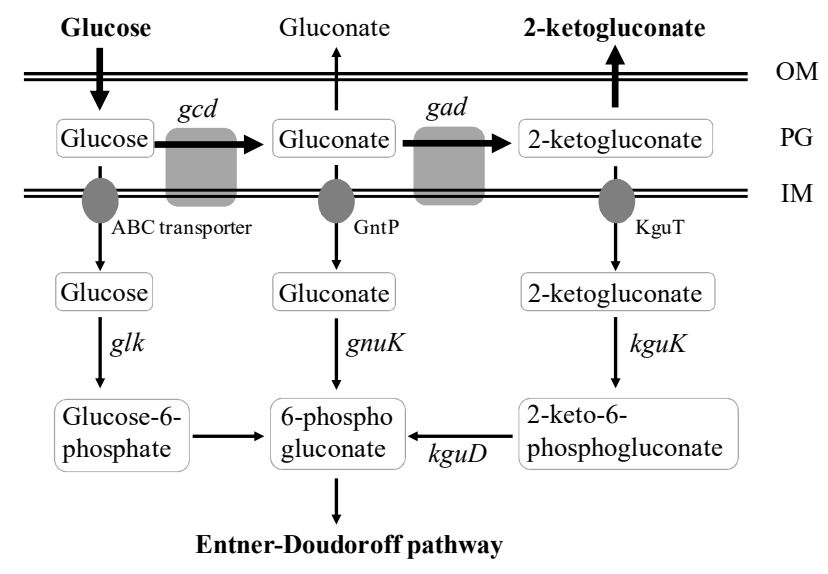

Figure 1. Schematic representation of 2-ketogluconate (2KGA) biosynthesis and catabolism pathways in Pseudomonas. OM, outer membrane; PG, periplasmic space; IM, inner membrane; ABC transporter, ATP-binding cassette transporter; GntP, gluconate transporter; KguT, 2-ketogluconate transporter. Genes: $g c d$ encoding glucose dehydrogenase, gad encoding gluconate 2-dehydrogenase, $k g u K$ encoding 2-ketogluconate kinase, $\mathrm{kg} u \mathrm{D}$ encoding 2-keto-6-phosphogluconate reductase, glk encoding glucokinase, gnuK encoding gluconate kinase.

Free-living bacteria usually have a versatile metabolism that allows the use of many different compounds as a source of carbon and energy. Generally, bacteria cells can selectively assimilate a preferred compound among a mixture of several potential carbon sources, and this process is carbon catabolite repression. Catabolite repression is a mechanism preventing transcriptional expression of genes required for the degradation of less-preferred substrate in the presence of the preferred substrate $[15,16]$. Pseudomonas are ubiquitous bacteria, and a wide range of compounds can be assimilated by them. The most unusual is that the preferred carbon sources for Pseudomonas are some organic acids or amino acids, rather than glucose. For example, in the presence of succinate and glucose, the expression of enzymes in the P. aeruginosa central pathway for glucose catabolism is repressed until succinate is consumed [15]. When P. putida KT2440 strain is cultured with succinate, glucose, gluconate, or 2KGA as the sole carbon source, succinate promotes the fastest growth, followed by gluconate and then by glucose, and 2KGA leads to the slowest growth. Thus, succinate is the most preferred substrate, and 2KGA is the least preferred substrate [11]. Glucose is used in preference to phenylacetic acid (PAA) when P. putida KT2440 strain is cultured in the presence of glucose and PAA, and the PAA catabolic genes are repressed by the presence of glucose [17]. However, for P. putida CSV86 strain, metabolic and transport studies demonstrate that glucose metabolism is suppressed when this strain is grown on aromatic compounds or organic acids [18]. Until now, there is almost no detailed research on the carbon catabolite repression of 2KGA metabolism by glucose in Pseudomonas strain. 
P. plecoglossicida JUIM01 strain can synthesis 2KGA by using glucose as the substrate and currently used for erythorbic acid production in China [7]. In addition, there is no research on the relationship between glucose and 2KGA metabolism in P. plecoglossicida strain. In this study, we found that P. plecoglossicida JUIM01 could convert glucose to 2KGA extracellularly, and the formed 2KGA was subsequently consumed during later growth phase. Then, the mechanism of this phenomenon was investigated at transcription and protein levels. Finally, the consumption of 2KGA was attenuated by supplementation of sufficient glucose, and the 2KGA yield from glucose reached a high level.

\section{Results and Discussion}

\subsection{KGA Production and Consumption by P. plecoglossicida JUIM01 at Low Initial Glucose Concentration}

As mentioned above, P. plecoglossicida JUIM01 strain can synthesis 2KGA by using glucose as the substrate, and is an important industrial 2KGA producer in China [7]. In addition, some Pseudomonas strains can use not only glucose, but also 2KGA as the sole carbon source for cell growth $[11,13]$. In order to analysis the relationship between glucose and 2KGA metabolism in P. plecoglossicida, strain cultivation experiments with low glucose concentration in culture broth were performed.

The time course of 2KGA production and consumption by P. plecoglossicida JUIM01, when the initial glucose concentration of fermentation medium was $14 \mathrm{~g} / \mathrm{L}$, is shown in Figure 2a. At $10 \mathrm{~h}$ of fermentation, $10.5 \mathrm{~g} / \mathrm{L}$ of $2 \mathrm{KGA}$ was produced, and almost all the glucose was consumed. After glucose depletion, the strain started to consume the product 2KGA. This phenomenon is very similar to that described by Fuhrer et al. [13].
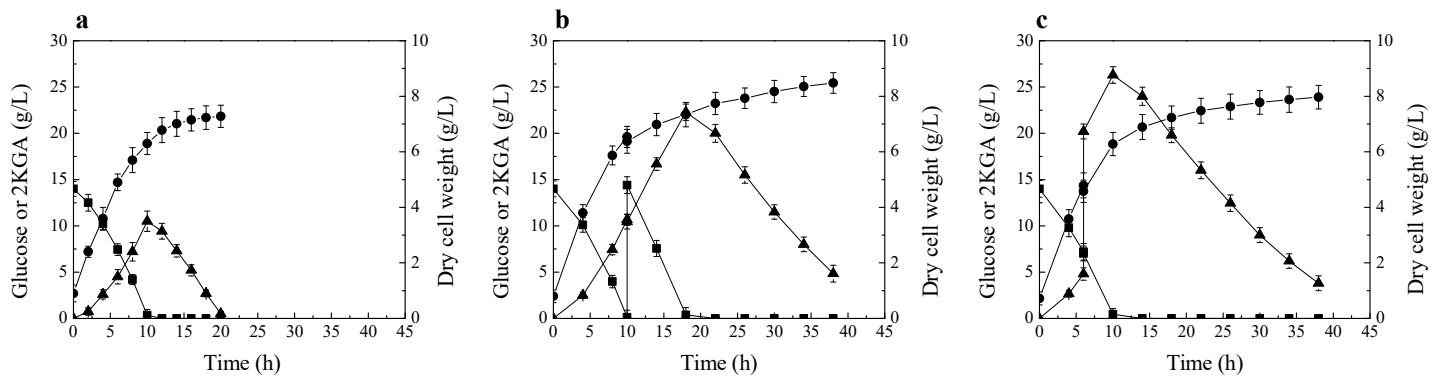

Figure 2. 2KGA production and consumption by P. plecoglossicida JUIM01 at low initial glucose concentration. (a) 2KGA fermentation without glucose and 2KGA supplementation; (b) Glucose supplementation experiment; (c) 2KGA supplementation experiment. Signal denotes: filled triangle-2KGA, filled square - glucose, filled circle — dry cell weight. The error bars represent the standard deviation of three independent replicates.

Next, another 2KGA fermentation by P. plecoglossicida JUIM01 was performed. In this fermentation process, $14 \mathrm{~g} / \mathrm{L}$ of glucose was fed into fermentation broth after glucose was exhausted. As shown in Figure 2b, after the supplementation of glucose, the strain continued to produce 2KGA by using glucose; only when the glucose in fermentation broth was exhausted did the strain start to consume the product 2KGA.

Then, the experiment of 2KGA supplementation during the fermentation process was performed. During the fermentation process, $15 \mathrm{~g} / \mathrm{L}$ of $2 \mathrm{KGA}$ was fed into the fermentation broth before glucose was exhausted. As shown in Figure 2c, after supplementing 2KGA, the strain continued to produce 2KGA by using the residual glucose in fermentation broth; similarly, only when the glucose was exhausted did the strain start to consume the product 2KGA.

As mentioned above, free-living bacteria usually have a versatile metabolism and can selectively assimilate a preferred compound through cell regulatory effects of carbon catabolite repression of gene expression $[15,16]$. Until now, there is almost no detailed research on the carbon catabolite repression of 2KGA metabolism by glucose in Pseudomonas strain, and there is no research on the relationship between glucose and 2KGA metabolism in P. plecoglossicida strain. The results of these three 
experiments of 2KGA fermentation by P. plecoglossicida JUIM01 at low initial glucose concentration indicate that P. plecoglossicida JUIM01 possesses carbon catabolite repression of 2KGA metabolism by glucose. Only after the glucose was exhausted did the strain start to assimilate 2KGA for cell growth and maintenance.

\subsection{Transcription and Proteomics Studies on 2KGA Consumption by P. plecoglossicida JUIM01}

The transcription levels of $g c d, g a d, k g u K, k g u D, g l k$, and $g n u K$ genes were studied during 2KGA fermentation by P. plecoglossicida JUIM01 with initial glucose concentration of $14 \mathrm{~g} / \mathrm{L}$, and without glucose and 2KGA supplementation. The results are shown in Table 1. In the initial stage of fermentation, 2KGA was produced by P. plecoglossicida JUIM01 using glucose (Figure 2a). Meanwhile, the transcription levels of $g c d$ and $g a d$ genes for 2KGA biosynthesis were increased before $12 \mathrm{~h}$ of fermentation process, especially the gcd gene. In the later phase of fermentation, all the glucose was consumed, and the strain started to consume the product 2KGA (Figure 2a). In the meantime, the transcription levels of $\mathrm{kguK}$ and $\mathrm{kguD}$ genes for $2 \mathrm{KGA}$ metabolism were increased significantly. The transcription levels of $g l k$ and $g n u K$ genes for glucose and gluconate metabolism, respectively, showed no remarkable change (Table 1). The transcription analysis of 2KGA biosynthesis and metabolism genes indicates that $P$. plecoglossicida JUIM01 possesses carbon catabolite repression. The transcriptional expression of genes in P. plecoglossicida JUIM01 required for the degradation of 2KGA was repressed until glucose was depleted.

Table 1. Relative transcriptional levels of genes for 2KGA biosynthesis and metabolism at different fermentation phases.

\begin{tabular}{ccccccc}
\hline \multirow{2}{*}{ Time (h) } & \multicolumn{6}{c}{ Relative Transcriptional Levels } \\
\cline { 2 - 7 } & gcd & gad & kguK & kguD & glk & gnuK \\
\hline 4 & $1.0 \pm 0.2$ & $1.0 \pm 0.3$ & $1.0 \pm 0.2$ & $1.0 \pm 0.2$ & $1.0 \pm 0.1$ & $1.0 \pm 0.2$ \\
8 & $1.1 \pm 0.3$ & $1.2 \pm 0.2$ & $1.1 \pm 0.1$ & $1.6 \pm 0.3$ & $0.5 \pm 0.2$ & $0.7 \pm 0.2$ \\
12 & $6.2 \pm 1.5$ & $1.7 \pm 0.4$ & $2.0 \pm 0.6$ & $4.5 \pm 1.4$ & $3.0 \pm 0.9$ & $0.9 \pm 0.4$ \\
16 & $5.0 \pm 2.1$ & $1.5 \pm 0.3$ & $14.2 \pm 2.5$ & $11.8 \pm 2.0$ & $1.7 \pm 0.4$ & $1.6 \pm 0.5$ \\
\hline
\end{tabular}

For proteomics analysis, whole-cell protein extraction was performed at the middle stages of 2KGA production phase and consumption phase, during 2KGA fermentation by P. plecoglossicida JUIM01 with the initial glucose concentration of $14 \mathrm{~g} / \mathrm{L}$, and without glucose and 2KGA supplementation. In the 2KGA consumption phase, 11 proteins were upregulated in expression and 23 proteins were downregulated in expression, compared to those in 2KGA production phase (Figure S1, Tables S1 and S2). In 2KGA consumption phase, 2 ATP-binding cassette transporters (protein spots 5419 and 5423) were upregulated in expression, and it is speculated that the cell needed to assimilate amino acids for cell growth and maintenance after all the glucose was consumed. Several proteins (protein spots 2107, 5220, 5311, and 6423), participating in cellular metabolic reactions, were upregulated in expression; this is probably due to the change of cellular metabolism when 2KGA was used as a substrate by the cell (Table S1). In the 2KGA consumption phase, the proteins participating in biosynthesis of amino acids (protein spots 6518 and 6519), nucleotides (protein spot 6714), and fatty acids (protein spot 6514, 7113, and 7612), were downregulated in expression (Table S2). The protein 1034 is a component of ribosome, and the protein 6420 is used for peptidoglycan biosynthesis; these two proteins participate in protein synthesis and cell wall formation, and their expression levels were downregulated (Table S2). In the 2KGA consumption phase, many proteins participating in cell growth were downregulated in expression; thus, the cell growth rate was decreased (Figure 2a).

The transcription analysis in 2KGA fermentation by P. plecoglossicida JUIM01 revealed that the transcription levels of genes for 2KGA metabolism were significantly increased (more than 10 times) after glucose depletion. However, the proteomics study by 2-DE could not detect the proteins participating in 2KGA metabolism and their changes in expression. This was perhaps a result of 
the limitations of protein fractionation by 2-DE. The proteins participating in 2KGA metabolism could not be isolated and identified in the process [19]. Besides, the gene expression variation at translation is more conserved than transcription, mostly due to the buffering effect of translational regulation for the transcriptional divergence [20]. Although there were changes in expression of the proteins participating in 2KGA metabolism, the changes were less significant. In the future, the quantitative iTRAQ LC-MS/MS proteomics can be used to perform a more global detection and functional inference of proteins involved in 2KGA metabolism and carbon catabolite repression of 2KGA metabolism by glucose $[21,22]$.

\subsection{Attenuation of 2 KGA Consumption by Increasing the Supply of Glucose}

The above studies indicated that P. plecoglossicida JUIM01 possesses carbon catabolite repression, and glucose is the preferred carbon source compared to 2KGA. Glucose in culture broth can repress the 2KGA metabolism by P. plecoglossicida JUIM01. In order to attenuate 2KGA consumption by P. plecoglossicida JUIM01, the initial glucose concentration of fermentation medium was increased. Time courses of 2KGA production and consumption at different initial glucose concentrations by P. plecoglossicida JUIM01 are shown in Figure 3. These results showed that increasing the initial glucose concentration of the fermentation medium was effective in attenuating 2KGA consumption after glucose depletion. This is probably because the cell vitality of P. plecoglossicida JUIM01 declined after a long time of cultivation, and the vitality decline became more and more serious, along with the prolonged cultivation process. More importantly, the 2KGA yield from glucose was enhanced, along with the increased initial glucose concentration of fermentation medium, when 2KGA concentration reached the highest point (Table 2). This is mostly because the proportion of glucose used for biomass or cell growth decreased and, thus, the proportion of glucose used for 2KGA production was enhanced with the increased glucose supply (Table 2). However, excessive glucose concentration in the fermentation medium had an adverse effect on cell growth and 2KGA production rate (Figure 3).
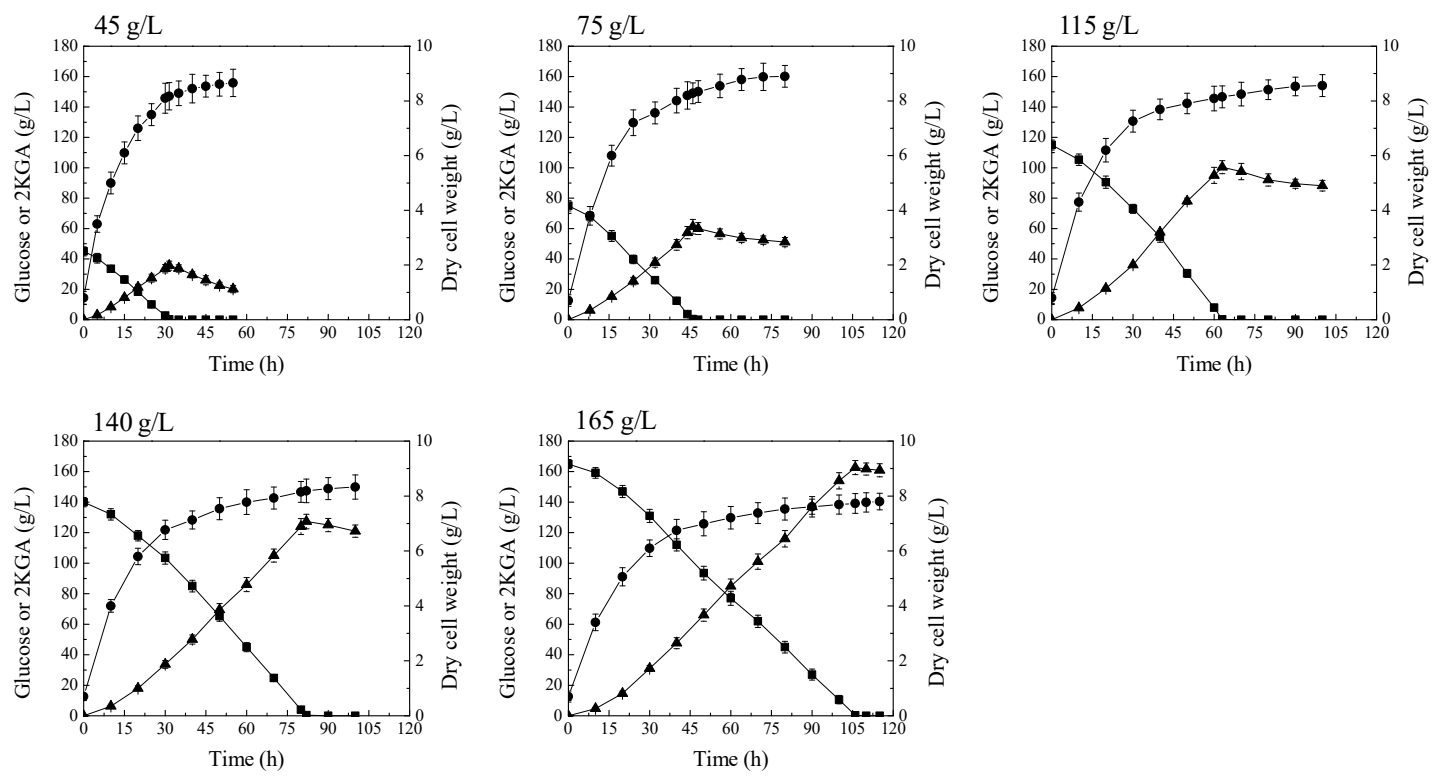

Figure 3. Attenuation of 2KGA consumption by increasing the supply of glucose. Signal denotes: filled triangle-2KGA, filled square-glucose, filled circle-dry cell weight. The error bars represent the standard deviation of three independent replicates. 
Table 2. 2KGA batch fermentation parameters at different initial glucose concentrations when the 2KGA concentration reached the highest point.

\begin{tabular}{cccccc}
\hline Glucose (g/L) & $\begin{array}{c}\text { 2KGA Production } \\
(\mathbf{g} / \mathbf{L})\end{array}$ & $\begin{array}{c}\text { 2KGA Yield on } \\
\text { Glucose }(\mathbf{g} / \mathbf{g})\end{array}$ & $\begin{array}{c}\text { Productivity } \\
(\mathbf{g} / \mathrm{L} / \mathbf{h})\end{array}$ & Biomass $(\mathrm{g} / \mathrm{L})$ & $\begin{array}{c}\text { Biomass Yield on } \\
\text { Glucose }(\mathbf{g} / \mathbf{g})\end{array}$ \\
\hline 45 & $35.6 \pm 3.0$ & $0.79 \pm 0.07$ & $1.13 \pm 0.09$ & 8.2 & 0.18 \\
75 & $61.2 \pm 4.8$ & $0.82 \pm 0.06$ & $1.33 \pm 0.10$ & 8.2 & 0.11 \\
115 & $100.4 \pm 4.3$ & $0.87 \pm 0.04$ & $1.58 \pm 0.07$ & 8.1 & 0.07 \\
140 & $127.3 \pm 4.6$ & $0.91 \pm 0.03$ & $1.55 \pm 0.06$ & 8.0 & 0.06 \\
165 & $162.7 \pm 4.8$ & $0.99 \pm 0.03$ & $1.53 \pm 0.04$ & 7.7 & 0.05 \\
\hline
\end{tabular}

\subsection{Fed-Batch Fermentation of P. plecoglossicida JUIM01 for 2KGA Production}

The production performance of P. plecoglossicida JUIM01 was investigated in fed-batch process. Figure 4 shows the time profiles of fed-batch fermentations in $30 \mathrm{~L}$ bioreactors. Fed-batch fermentation of P. plecoglossicida JUIM01 resulted in $205.67 \mathrm{~g} / \mathrm{L}$ of $2 \mathrm{KGA}$ with a productivity of $6.86 \mathrm{~g} / \mathrm{L} / \mathrm{h}$ and yield of $0.953 \mathrm{~g} / \mathrm{g}$ glucose. The final concentration and productivity of 2KGA in fed-batch fermentation process were significantly increased compared to batch fermentation in shake flasks. This is because the biosynthesis of 2KGA is an oxidation process of glucose, and the oxygen supply of fermentation in a stirred fermenter is more abundant than that of fermentation in shake flasks [9,11]. In addition, fed-batch fermentation can attenuate the adverse effects of excessive glucose concentration, in the fermentation medium, on cell growth. Under optimum conditions, K. pneumoniae could produce $186 \mathrm{~g} / \mathrm{L}$ of 2 KGA with a productivity of $7.15 \mathrm{~g} / \mathrm{L} / \mathrm{h}$, and yield $1.05 \mathrm{~g} / \mathrm{g}$ of glucose using a two-stage fermentation strategy, and the productivity and yield from glucose is the highest in the research of 2KGA production by direct fermentation [6]. Therefore, P. plecoglossicida JUIM01 has great competitiveness and practicability for 2KGA production by direct fermentation.

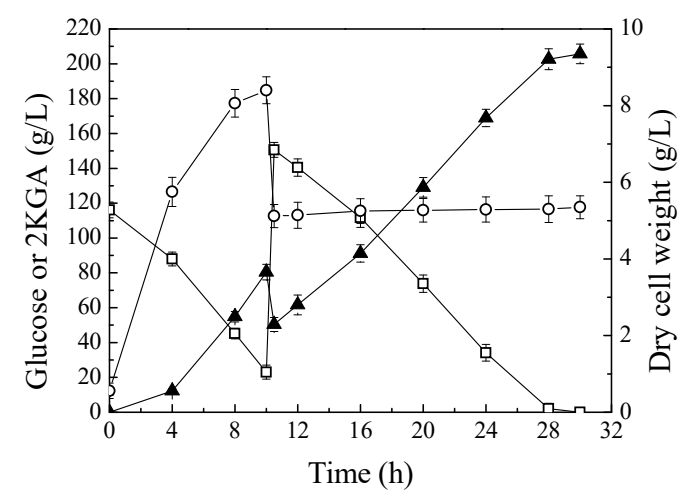

Figure 4. Fed-batch fermentation of P. plecoglossicida JUIM01 for 2KGA production. Signal denotes: filled triangle-2KGA, empty square—glucose, empty circle—dry cell weight. The error bars represent the standard deviation of three independent replicates.

Metabolic engineering has proven to be important in developing competitive microbial strains for the production of diverse chemicals [23-26]. Until now, almost all of the metabolic engineering work for 2KGA production were focused on the 2KGA synthesis pathway, including glucose dehydrogenase and gluconate 2-dehydrogenase $[8,9,27]$. In the future, studies on the detailed relationship between 2KGA synthesis, glucose metabolism, and cell growth and maintenance, will provide valuable information for 2KGA production. On this basis, systems metabolic engineering, for optimizing the relationship among 2KGA synthesis, glucose metabolism, and cell growth and maintenance, will further increase the 2KGA production efficiency. 


\section{Materials and Methods}

\subsection{Microorganism and Cultivation Conditions}

P. plecoglossicida JUIM01 strain, that was screened and stored in our laboratory, is an important industrial 2KGA producer, and has been deposited in the China General Microbiological Culture Collection Center (CGMCC) under collection number CGMCC No. 7150 [7]. The strain was maintained on slant medium containing peptone $10 \mathrm{~g} / \mathrm{L}$, beef extract $5 \mathrm{~g} / \mathrm{L}, \mathrm{NaCl} 5 \mathrm{~g} / \mathrm{L}$, and agar $20 \mathrm{~g} / \mathrm{L}$. The strain from agar slants was inoculated in $50 \mathrm{~mL}$ seed medium containing glucose $20 \mathrm{~g} / \mathrm{L}$, corn steep liquor $5 \mathrm{~g} / \mathrm{L}$, urea $2 \mathrm{~g} / \mathrm{L}, \mathrm{KH}_{2} \mathrm{PO}_{4} 2 \mathrm{~g} / \mathrm{L}, \mathrm{MgSO}_{4} \cdot 7 \mathrm{H}_{2} \mathrm{O} 0.5 \mathrm{~g} / \mathrm{L}, \mathrm{CaCO}_{3} 1 \mathrm{~g} / \mathrm{L}$, and cultured at $30^{\circ} \mathrm{C}$ for $18 \mathrm{~h}$ in $500 \mathrm{~mL}$ shake flasks with a rotational speed of $265 \mathrm{rpm}$. The seed culture $(5 \mathrm{~mL})$ was transferred into $500 \mathrm{~mL}$ shake flasks containing $50 \mathrm{~mL}$ fermentation medium, and cultured at $30^{\circ} \mathrm{C}$ with a rotational speed of $265 \mathrm{rpm}$. The fermentation medium contained corn steep liquor $5 \mathrm{~g} / \mathrm{L}$, urea $2 \mathrm{~g} / \mathrm{L}, \mathrm{KH}_{2} \mathrm{PO}_{4}$ $2 \mathrm{~g} / \mathrm{L}, \mathrm{MgSO}_{4} \cdot 7 \mathrm{H}_{2} \mathrm{O} 0.5 \mathrm{~g} / \mathrm{L}$, the glucose concentration of the fermentation medium was adjusted to the desired levels according to the experimental design, and $\mathrm{CaCO}_{3}$ was added for balancing the $\mathrm{pH}$ from 5.0 to 6.5, and its concentration was a quarter of the glucose concentration.

For 2KGA fed-batch fermentation, the experiments were carried out at $30 \mathrm{~L}$ lab scale in a mechanically stirred fermenter (GRJ-30D, Green Bio-engineering Co. Ltd., Zhenjiang, China). The seed culture $(1.5 \mathrm{~L})$ was obtained as described above. The seed culture was transferred into the $30 \mathrm{~L}$ stirred fermenter containing $15 \mathrm{~L}$ fermentation medium, consisting of glucose $115 \mathrm{~g} / \mathrm{L}$, corn steep liquor $5 \mathrm{~g} / \mathrm{L}$, urea $2 \mathrm{~g} / \mathrm{L}, \mathrm{KH}_{2} \mathrm{PO}_{4} 2 \mathrm{~g} / \mathrm{L}, \mathrm{MgSO}_{4} \cdot 7 \mathrm{H}_{2} \mathrm{O} 0.5 \mathrm{~g} / \mathrm{L}, \mathrm{CaCO}_{3} 35 \mathrm{~g} / \mathrm{L}$, and antifoaming agent $0.2 \mathrm{~g} / \mathrm{L}$. The feed medium $\left(9 \mathrm{~L}\right.$ ) consisting of glucose $350 \mathrm{~g} / \mathrm{L}$ and $\mathrm{CaCO}_{3} 100 \mathrm{~g} / \mathrm{L}$, was fed into the fermenter when the residual concentration of glucose went below $20-25 \mathrm{~g} / \mathrm{L}$. The fed-batch fermentations were performed at $30^{\circ} \mathrm{C}$, the agitation speed was controlled at $440 \mathrm{rpm}$, and the air flow rate was maintained at $1.5 \mathrm{vvm}$.

\subsection{Analytical Methods}

Dry cell weight (DCW) was determined from a calibration curve of known DCW and the corresponding optical density at $650 \mathrm{~nm}\left(\mathrm{DCW}=0.44 \times \mathrm{OD}_{650}, \mathrm{~g} / \mathrm{L}\right)$ using a spectrophotometer (Biospec-1601 spectrophotometer, Shimadzu) [3]. For quantification of substrate consumption and product formation, samples of the culture were harvested and spun down $\left(10,000 \mathrm{~g}, 5 \mathrm{~min}\right.$, and $\left.4{ }^{\circ} \mathrm{C}\right)$. Glucose concentration was determined using a Biosensor Analyzer (Biology Institute of Shandong Academy of Sciences, Jinan, China). The concentration of 2KGA was determined and calculated on the basis of glucose concentration, using a polarimetry method [3,7]. All experiments were carried out in triplicates, independently, and the results were the average of three replicate experiments.

\subsection{Transcriptional Analysis}

Total RNA was extracted from P. plecoglossicida JUIM01 cells at different time points of the cultivation using the RNAiso Plus reagent (Takara, Dalian, China). cDNA was synthesized using a PrimeScript RT reagent kit (Takara, Dalian, China). Real-time PCR (RT-PCR) was performed as described by Zhang et al. 2013 [28]. Normalization of the results was performed by using $r p o D$ as the housekeeping gene, and the relative abundance of $r p o D$ gene was used as the internal standard [29]. The primers used for RT-PCR analysis are listed in Table 3. All the experiments were carried out in triplicates independently, and the results were the average of three replicate experiments. 
Table 3. Primers used for RT-PCR analysis.

\begin{tabular}{cc}
\hline Name & Sequence $\left(\mathbf{5}^{\prime} \rightarrow \mathbf{3}^{\prime}\right)$ \\
\hline$r p o D F$ & GATTCGTCAGGCGATCAC \\
$r p o D R$ & AATACGGTTGAGTTGTTGA \\
$g c d \mathrm{~F}$ & ACCAGTACCTGCGTGCCTAT \\
$g c d \mathrm{R}$ & CCTTGCCGGTGTAGGTCAT \\
$g a d \mathrm{~F}$ & TTTCATGGATTGGGTGGAAC \\
$g a d \mathrm{R}$ & CGCATCGACTTTCTTCATCA \\
$k g u K \mathrm{~F}$ & GCGACCCGCAAGTGGAATAC \\
$k g u K \mathrm{R}$ & GAAGGAGATGCTGCGACCGT \\
$k g u D F$ & CCGAAACCACTGCCGACACC \\
$k g u D R$ & ACGATGCCCAGCGTCTTGC \\
$g l k \mathrm{~F}$ & CTGCATGAGCGGGTATTTC \\
$g l k \mathrm{R}$ & ATGATCCAACGCCTGCTG \\
$g n u K F$ & GTTCGGACTGGCTACTGATACC \\
$g n u K R$ & ACCGCCAAAGCCGTCCT \\
\hline
\end{tabular}

\subsection{Whole-Cell Protein Extraction, Two-Dimensional Gel Electrophoresis, and Protein Identification}

Sample preparation was performed at the middle stages of 2KGA production phase and the consumption phase. Cells were harvested by centrifugation $\left(10,000 \times g, 1 \mathrm{~min}\right.$, and $\left.4{ }^{\circ} \mathrm{C}\right)$ and immediately frozen in liquid nitrogen. The whole-cell protein extraction was performed according to reference [30]. Proteins were separated by two-dimensional gel electrophoresis (2-DE). For isoelectric focusing, $1 \mathrm{mg}$ of proteins were diluted in the immobilized $\mathrm{pH}$ gradient (IPG) strip rehydration buffer $(450 \mu \mathrm{L})$. The protein solution was loaded on $24 \mathrm{~cm}$ IPG strips (GE Healthcare) that provided a linear gradient from $\mathrm{pH} 3$ to 10, according to the manufacturer's instructions. Isoelectric focusing and sodium dodecyl sulfate (SDS)-polyacrylamide electrophoresis were carried out according to references [30,31]. Stained 2-DE gels were scanned using an ImageScanner III (GE Healthcare) and analyzed by PDQuest 2-D Analysis Software (Bio-Rad). Protein spots of interest were cut from the gels and trypsin digested in-gel, as described, and identified by MALDI-TOF/TOF tandem MS using an AB SCIEX 5800 MALDI TOF/TOF mass spectrometer (AB SCIEX, USA). MS data were analyzed using the MASCOT 2.1.0 program (Matrix Science, MA), as described [30-32].

\section{Conclusions}

In this paper, we found the 2KGA-producing strain, P. plecoglossicida JUIM01, could consume 2KGA after glucose depletion during the fermentation process. Glucose and 2KGA supplementation experiments, and transcription analysis of 2KGA biosynthesis and metabolism genes, indicated that P. plecoglossicida JUIM01 exhibits carbon catabolite repression of 2KGA metabolism by glucose. The consumption of 2KGA by P. plecoglossicida JUIM01 was attenuated by supplement of sufficient glucose, and the final concentration and productivity of 2KGA could reach $205.67 \mathrm{~g} / \mathrm{L}$ and $6.86 \mathrm{~g} / \mathrm{L} / \mathrm{h}$, respectively, during fed-batch fermentation of P. plecoglossicida JUIM01. Further systematic studies on the consumption of 2KGA by P. plecoglossicida JUIM01, using genome-wide metabolic model in combination with integrated omics analysis, can provide important guidance for the industrial fermentation production of 2KGA.

Supplementary Materials: The supplementary materials are available online.

Author Contributions: Investigation, T.A. and F.X.; Methodology, W.S., Z.M., F.C. and X.Q.; Project administration, W.S. and Z.M.; Resources, W.S.; Writing—original draft, Z.M.; Writing—review \& editing, W.S.

Funding: This research was funded by the National Natural Science Foundation of China grant number 31571885. The APC was funded by 31571885 . 
Acknowledgments: This work was supported by the National Natural Science Foundation of China (31571885), the National Natural Science Foundation of China (31700075), the National High Technology Research and Development Program (2012AA022103), the Science and Technology Program of Jiangxi Province ([2015]64), the Science and Technology Program of Dexing City ([2015]44), and a Project Funded by the Priority Academic Program Development of Jiangsu Higher Education Institutions.

Conflicts of Interest: The authors declare no conflict of interest.

\section{References}

1. Sun, W.J.; Liu, C.F.; Yu, L.; Cui, F.J.; Zhou, Q.; Yu, S.L.; Sun, L. A novel bacteriophage KSL-1 of 2-Keto-gluconic acid producer Pseudomonas fluorescens K1005: Isolation, characterization and its remedial action. BMC Microbiol. 2012, 12, 127. [CrossRef] [PubMed]

2. Sun, W.; Xiao, F.; Wei, Z.; Cui, F.; Yu, L.; Yu, S.; Zhou, Q. Non-sterile and buffer-free bioconversion of glucose to 2-keto-gluconic acid by using Pseudomonas fluorescens AR4 free resting cells. Process Biochem. 2015, 50, 493-499. [CrossRef]

3. Sun, W.J.; Zhou, Y.Z.; Zhou, Q.; Cui, F.J.; Yu, S.L.; Sun, L. Semi-continuous production of 2-keto-gluconic acid by Pseudomonas fluorescens AR4 from rice starch hydrolysate. Bioresour. Technol. 2012, 110, 546-551. [CrossRef] [PubMed]

4. Kiefler, I.; Bringer, S.; Bott, M. Metabolic engineering of Gluconobacter oxydans $621 \mathrm{H}$ for increased biomass yield. Appl. Microbiol. Biotechnol. 2017, 101, 5453-5467. [CrossRef] [PubMed]

5. Krajewski, V.; Simic, P.; Mouncey, N.J.; Bringer, S.; Sahm, H.; Bott, M. Metabolic engineering of Gluconobacter oxydans for improved growth rate and growth yield on glucose by elimination of gluconate formation. Appl. Environ. Microbiol. 2010, 76, 4369-4376. [CrossRef] [PubMed]

6. Sun, Y.; Wei, D.; Shi, J.; Mojović, L.; Han, Z.; Hao, J. Two-stage fermentation for 2-Ketogluconic acid production by Klebsiella pneumoniae. J. Microbiol. Biotechnol. 2014, 24, 781-787. [CrossRef] [PubMed]

7. Sun, W.; Wang, Q.; Luan, F.; Man, Z.; Cui, F.; Qi, X. The role of kguT gene in 2-ketogluconate-producing Pseudomonas plecoglossicida JUIM01. Appl. Biochem. Biotechnol. 2018. [CrossRef] [PubMed]

8. Yi, X.; Li, T.; Wang, B.; Liu, J.; Du, H.; Feng, H. Production of 2-Keto-D-gluconic acid by metabolically engineered Gluconobacter suboxydans. China Biotechnol. 2014, 34, 97-106.

9. Li, K.; Mao, X.; Liu, L.; Lin, J.; Sun, M.; Wei, D.; Yang, S. Overexpression of membrane-bound gluconate-2-dehydrogenase to enhance the production of 2-keto-d-gluconic acid by Gluconobacter oxydans. Microb. Cell Fact. 2016, 15, 121. [CrossRef] [PubMed]

10. del Castillo, T.; Ramos, J.L.; Rodríguez-Herva, J.J.; Fuhrer, T.; Sauer, U.; Duque, E. Convergent peripheral pathways catalyze initial glucose catabolism in Pseudomonas putida: Genomic and flux analysis. J. Bacteriol. 2007, 189, 5142-5152. [CrossRef] [PubMed]

11. Nikel, P.I.; Chavarría, M.; Fuhrer, T.; Sauer, U.; de Lorenzo, V. Pseudomonas putida KT2440 strain metabolizes glucose through a cycle formed by enzymes of the Entner-Doudoroff, Embden-Meyerhof-Parnas, and Pentose Phosphate Pathways. J. Biol. Chem. 2015, 290, 25920-25932. [CrossRef] [PubMed]

12. Kim, J.; Jeon, C.O.; Park, W. Dual regulation of zwf-1 by both 2-keto-3-deoxy-6-phosphogluconate and oxidative stress in Pseudomonas putida. Microbiology 2008, 154, 3905-3916. [CrossRef] [PubMed]

13. Fuhrer, T.; Fischer, E.; Sauer, U. Experimental identification and quantification of glucose metabolism in seven bacterial species. J. Bacteriol. 2005, 187, 1581-1590. [CrossRef] [PubMed]

14. del Castillo, T.; Ramos, J.L. Simultaneous catabolite repression between glucose and toluene metabolism in Pseudomonas putida is channeled through different signaling pathways. J. Bacteriol. 2007, 189, 6602-6610. [CrossRef] [PubMed]

15. Rojo, F. Carbon catabolite repression in Pseudomonas: Optimizing metabolic versatility and interactions with the environment. FEMS Microbiol. Rev. 2010, 34, 658-684. [CrossRef] [PubMed]

16. Sonnleitner, E.; Abdou, L.; Haas, D. Small RNA as global regulator of carbon catabolite repression in Pseudomonas aeruginosa. Proc. Natl. Acad. Sci. USA 2009, 106, 21866-21871. [CrossRef] [PubMed]

17. Kim, J.; Yeom, J.; Jeon, C.O.; Park, W. Intracellular 2-keto-3-deoxy-6-phosphogluconate is the signal for carbon catabolite repression of phenylacetic acid metabolism in Pseudomonas putida KT2440. Microbiology 2009, 155, 2420-2428. [CrossRef] [PubMed]

18. Basu, A.; Phale, P.S. Inducible uptake and metabolism of glucose by the phosphorylative pathway in Pseudomonas putida CSV86. FEMS Microbiol. Lett. 2006, 259, 311-316. [CrossRef] [PubMed] 
19. Liang, C.R.M.Y.; Leow, C.K.; Neo, J.C.H.; Tan, G.S.; Lo, S.L.; Lim, J.W.E.; Seow, T.K.; Lai, P.B.S.; Chung, M.C.M. Proteome analysis of human hepatocellular carcinoma tissues by two-dimensional difference gel electrophoresis and mass spectrometry. Proteomics 2005, 5, 2258-2271. [CrossRef] [PubMed]

20. Wang, Z.; Sun, X.; Zhao, Y.; Guo, X.; Jiang, H.; Li, H.; Gu, Z. Evolution of gene regulation during transcription and translation. Genome Biol. Evol. 2015, 7, 1155-1167. [CrossRef] [PubMed]

21. Qiao, J.; Shao, M.; Chen, L.; Wang, J.; Wu, G.; Tian, X.; Liu, J.; Huang, S.; Zhang, W. Systematic characterization of hypothetical proteins in Synechocystis sp. PCC 6803 reveals proteins functionally relevant to stress responses. Gene 2013, 512, 6-15. [CrossRef] [PubMed]

22. Qiao, J.; Wang, J.; Chen, L.; Tian, X.; Huang, S.; Ren, X.; Zhang, W. Quantitative iTRAQ LC-MS/MS proteomics reveals metabolic responses to biofuel ethanol in cyanobacterial Synechocystis sp. PCC 6803. J. Proteome Res. 2012, 11, 5286-5300. [CrossRef] [PubMed]

23. Man, Z.; Rao, Z.; Xu, M.; Guo, J.; Yang, T.; Zhang, X.; Xu, Z. Improvement of the intracellular environment for enhancing L-arginine production of Corynebacterium glutamicum by inactivation of $\mathrm{H}_{2} \mathrm{O}_{2}$-forming flavin reductases and optimization of ATP supply. Metab. Eng. 2016, 38, 310-321. [CrossRef] [PubMed]

24. Zhang, X.; Zhang, R.; Bao, T.; Rao, Z.; Yang, T.; Xu, M.; Xu, Z.; Li, H.; Yang, S. The rebalanced pathway significantly enhances acetoin production by disruption of acetoin reductase gene and moderate-expression of a new water-forming NADH oxidase in Bacillus subtilis. Metab. Eng. 2014, 23, 34-41. [CrossRef] [PubMed]

25. Man, Z.; Xu, M.; Rao, Z.; Guo, J.; Yang, T.; Zhang, X.; Xu, Z. Systems pathway engineering of Corynebacterium crenatum for improved L-arginine production. Sci. Rep. 2016, 6, 28629. [CrossRef] [PubMed]

26. Guo, J.; Man, Z.; Rao, Z.; Xu, M.; Yang, T.; Zhang, X.; Xu, Z. Improvement of the ammonia assimilation for enhancing L-arginine production of Corynebacterium crenatum. J. Ind. Microbiol. Biotechnol. 2017, 44, 443-451. [CrossRef] [PubMed]

27. Merfort, M.; Herrmann, U.; Ha, S.W.; Elfari, M.; Bringer-Meyer, S.; Görisch, H.; Sahm, H. Modification of the membrane-bound glucose oxidation system in Gluconobacter oxydans significantly increases gluconate and 5-keto-D-gluconic acid accumulation. Biotechnol. J. 2006, 1, 556-563. [CrossRef] [PubMed]

28. Zhang, X.; Zhang, R.; Bao, T.; Yang, T.; Xu, M.; Li, H.; Xu, Z.; Rao, Z. Moderate expression of the transcriptional regulator ALsR enhances acetoin production by Bacillus subtilis. J. Ind. Microbiol. Biotechnol. 2013, 40, 1067-1076. [CrossRef] [PubMed]

29. Kremmydas, G.F.; Tampakaki, A.P.; Georgakopoulos, D.G. Characterization of the biocontrol activity of Pseudomonas fluorescens strain $X$ reveals novel genes regulated by glucose. PLoS ONE 2013, 8, e61808. [CrossRef] [PubMed]

30. Gnoni, A.; Lippolis, R.; Zanotti, F.; Papa, S.; Palese, L.L. A two-dimensional electrophoresis and mass spectrometry protein analysis of the antibiotic producer Nonomuraea sp. ATCC 39727 in different growth conditions. FEMS Microbiol. Lett. 2007, 274, 35-41. [CrossRef] [PubMed]

31. Zhou, J.; Wang, K.; Xu, S.; Wu, J.; Liu, P.; Du, G.; Li, J.; Chen, J. Identification of membrane proteins associated with phenylpropanoid tolerance and transport in Escherichia coli BL21. J. Proteomics 2015, 113, 15-28. [CrossRef] [PubMed]

32. Jiang, W.; Du, B.; Chi, Z.; Ma, L.; Wang, S.; Zhang, X.; Wu, W.; Wang, X.; Xu, G.; Guo, C. Preliminary explorations of the role of mitochondrial proteins in refractory epilepsy: Some findings from comparative proteomics. J. Neurosci. Res. 2007, 85, 3160-3170. [CrossRef] [PubMed]

Sample Availability: Samples are available from the authors. 